\title{
The White Lion Volunteer Program in South Africa: A Study of Volunteer Needs
}

\author{
Tanya Boretti ${ }^{1}$, Felicité Fairer-Wessels ${ }^{2}$ \\ ${ }^{1,2}$ Division of Tourism Management, Faculty of Economic and Management Sciences, University of \\ Pretoria, Pretoria, South Africa
}

\begin{abstract}
Volunteer tourists are motivated to participate in volunteer programs due to their need to 'do something different', 'see another culture' and 'to escape', amongst others. The research aims to determine the internal and external factors that motivate individuals to participate in the Tsau! Global White Lion Protection Trust's (GWLPT) volunteer program. Maslow's theory of human motivation and Frankl's study of human behaviour are used to explore intrinsic factors whereas extrinsic or macro environmental factors of influence are also investigated. A mixed method approach with focus group discussions and an online survey is followed. A background to the volunteer program is presented with the activities available to volunteers. The key findings indicate that most volunteers are young females that volunteer for a minimum of two weeks; are internally motivated to 'give back and be useful' and 'to work with the white lions' for the purpose of self-actualisation. External motivation is mainly social in terms of concern about the well-being of the lions, and South Africa being an economically affordable destination. The GWLPT strives to fulfil the needs of volunteers, especially intrinsic needs associated with self-actualisation and self-transcendence.
\end{abstract}

\section{Introduction}

Modern society influences an individual's motivation to travel. Motivation refers to being provided with a reason or purpose to act in a certain way and travel creates a desire within an individual to participate in the trend. Abraham Maslow states that an individual with an unfulfilled need or desire will be motivated to complete the void and be sufficiently gratified; therefore an individual is motivated to travel to fulfil an unsatisfied need [1]. Volunteer tourism is a type of leisure tourism. A volunteer tourist is an individual who travels to another destination, either local or international, to undertake volunteering [2]. Individuals who participate in volunteer programs' rewards vary but generally includes education and learning; personal development; skills and work experience; and increased confidence [2].

The Global White Lion Protection Trust situated within the Timbavati Game Reserve, bordering the National Kruger Park offers a wildlife volunteer tourism project, called Tsau! Global White Lion Protection Trust's (GWLPT) that will be investigated for this research.

The GWLPT was founded in 2002 for conservation of the white lion and offers opportunities to volunteer or participate in an internship which includes a wide variety of different activities ranging from lion monitoring and tracking to anti-poaching patrols. Individuals from abroad and local 
individuals take part in this wildlife volunteer project since "the concept of 'volunteer tourism' is a growing trend in the tourism industry and is starting to draw attention..." [3]. This volunteer program attempts to satisfy volunteer tourists' needs by motivating them to engage in a variety of activities.

This research aims to identify the internal and external factors that motivate individuals to participate in the Tsau! White Lion Reintroduction Project volunteer program. The objectives of this research project are:

- to determine what motivates (internal) individuals to participate in a selected volunteer program, i.e. The Tsau! White lion volunteer program.

- to determine the external factors that influence volunteers in their choice of this selected program, i.e. The Tsau! White lion volunteer program.

Volunteer travelling was first introduced in the nineteenth century but since then there has been an influx in the diversity of volunteer programs from social, community conservation, ecological health and education [4]. Volunteering is a complex multi-dimensional concept and definitions for volunteering and volunteer tourism are debated to obtain clarity. [2] define formal volunteering as "an activity which takes place through not-for-profit organisations or projects and is undertaken to be of benefit to the community and the volunteer; of the volunteer's own free will and without coercion; for no financial payment; and in designated volunteer positions only" [2]. This definition is supported by Volunteering Australia [2] where the term volunteering essentially refers to a donation of time with no monetary incentive. However the concept of volunteer tourists is broader and is defined by [5] as "tourists who, for various reasons, volunteer in an organised way to undertake holidays that might involve aiding or alleviating the material poverty of some groups in society, the restoration of certain environments or research into aspects of society or environment" [5].

A volunteer tourist or a 'voluntourist' [4] is simply an individual who prefers allocating leisure travelling time to engage in volunteer programs and in so doing alleviate and aid circumstances in other communities' environments. Considering the two above-mentioned definitions of both the terms volunteering and volunteer tourist four consistent elements can be identified in both: free choice (free will, obligation to volunteer); remuneration (none at all, none expected, expenses reimbursed); structure (formal: planned/scheduled; informal: everyday humane gestures [6]; and intended beneficiaries (benefit/help others/strangers; help friends/relatives; benefit oneself) [2].

\section{People That Volunteer (Voluntourists)}

Certain individuals choose to use their vacations as an opportunity to engage and participate in volunteer programs and its associated activities. This study attempts to analyse the motivational factors that attribute to individuals' choice in participation in volunteer activities as a leisure time activity.

"The importance of motivation in tourism is quite obvious as it acts as a trigger that sets off all the events in travel" [3] and the motivators behind individuals' need to participate in volunteer programs are determined by both intrinsic and extrinsic motivating factors. Intrinsic factors as related to Maslow's 'hierarchy of needs' are self-actualisation, esteem needs, love needs, safety needs, and physiological need that form the basis for further development and applications to understand travel behaviour and the demand for tourism [3]. In addition to Maslow's theory of Human Motivation, Frankl's Logotherapy theory of man's search for meaning and self-transcendence is also discussed and additional intrinsic and extrinsic stimuli are considered in determining what factors increase an individual's propensity to volunteer.

\subsection{Intrinsic factors}

A state of wellbeing serves as an intrinsic attribution to an individual's motivation to engage in volunteerism. "The decision to visit a destination is a complex amalgam of needs, motivating an individual to set and prioritise goals in a belief that achieving these will satisfy the perceived needs" 
[3]. These perceived needs can be allocated to the five levels identified by Maslow's hierarchy and states that once an individual has satisfied one need, a higher need will emerge - hence the origin of the need-based hierarchy (i.e. physiological, safety, love/belonging) according to the need's relative propensity [7]. Summarizing tourist's motivators to participate in volunteer tourism, volunteerism has the potential to satisfy an individual's needs in the top three levels of the hierarchy (i.e. belonging, esteem, self-actualisation).

Affiliation needs or the need for love and/or belonging is expressed by volunteers who participate due to their need 'to network, to meet new people and develop friendships'. Esteem needs refer to a volunteer's need 'to do something different', 'to learn', '[to accept] a challenge' and 'to develop one's career'. The self-actualization need refers to "people's desire for self-fulfilment, namely the tendency for them to become actualized in what they are potentially" [7].

The need for self-actualisation is identified by a tourist's need to 'spread personal beliefs' and 'altruism (wanting to serve others, to improve other people's lives, to help).' This need refers to individual fulfilment, personal ambition, the desire to realise potential for achievement and aestheticism, which all constitute as psychological requirements [9]. Individuals who volunteer are therefore in pursuit of fulfilment within the higher level of the hierarchy which attributes to a volunteer's motivation to participate. Internal factors influencing volunteering participation rates are also associated with factors such as age and gender.

Frankl's observations of human behaviour led him to develop the Logotherapy theory that maintains that the will to meaning is a primary function in a human's (volunteer's) life. A human being has the ability to choose their own way, to rise above one's circumstances and make a difference. This human need to "aid and alleviate" one's surrounding circumstances is the core concept to volunteerism - essentially referring to a donation of time with no monetary incentive. Frankl's book 'Man's search for meaning' is based on the psychiatry of human behaviour, and based on the core belief that man's primary motivational search is his search for meaning [10].

"Today's [volunteer] has a need for self-actualisation, which is a prerequisite for selftranscendence; a state of experience that contributes to creativity and meaningful living". Both [7, 10], identified motivational and need theories which validate the purpose an individual finds within volunteerism. Maslow identified a basis for analysis of how an individual's satisfaction of a basic need, or lack thereof, affects their motivation and an individual's need for self-actualisation, which refers to personal fulfilment, as the main driver behind individual motivation. Whereas Frankl's studies of self-transcendence refer to "the ability to focus attention on doing something for the sake of others, as opposed to self-actualization, in which doing something for oneself is an end goal". Maslow and Frankl identified intrinsic factors that influence motivation whether it is for personal gain through fulfilment or in search of meaning. This is similar in volunteerism, where need and motivations stimulate reaction which manifests in participation and is driven by intrinsic stimuli.

\subsection{Extrinsic factors}

External factors of influence affect an individual's decision to participate in volunteering, such as time pressures from employment, financial barriers, mobility issues and a lack of knowledge about volunteering opportunities [2]. According to [2] labour market status or level of employment is an extrinsic influencing factor that increases an individual's likelihood to participate in programs. A relation can be drawn between the labour market status and particular socio-economic status. The GWLPT offers their volunteer programs at an approximate cost of $₫ 350$ per week excluding flights, food, and travel medical insurance. An employed individual is more likely to participate in volunteer programs (labour market status) since this would attribute to a higher level of socio-economic status. Volunteers therefore need to be financially capable to participate in the selected volunteer program. Other external factors include geographic location and length of residence, migration and civic and social participation.

With an individual's propensity to participate in a volunteer program varies determined by their internal and external influences, similarly the global development of volunteering is influenced by a 
range of macro environmental factors such as: sociocultural, political, economic [2], environmental, technological and legal. External environmental factors can thus either positively or negatively affect choices within an industry. A volunteer tourist/voluntourist travelling to a local or international destination to volunteer has external (macro environmental) factors to consider that may increase or decrease his/her propensity to volunteer.

\section{The Global White Lion Protection Trust (GWLPT)}

The Timbavati Game Reserve is situated within the Limpopo province in the northern part of South Africa. This private game reserve, bordering the Kruger National Park, is home to a rare type of lion, the white lion. A white lion is none other than a normal lion with a genetic mutation called chinchilla. This mutation in the lion's pigmentation causes the lions to have a lighter appearance than their feline counterparts. The occurrence of this genetic mutation is rare; hence the conservation of these lions has led to selective breeding in captivity. This rare genetic mutation has made the white lion an outcast in the wild. It is very difficult for the white lions to hunt prey since they are easily spotted. Their white complexions also make it easy for poachers to hunt them.

The GWLPT was founded in order to ensure the survival of this rare and unique genetic mutation [8]. The white lion also holds significant cultural value to the indigenous communities as these lions represent a national symbol of unity, peace and hope [8]. The Trust and the Timbavati region play host to the volunteering program established in this region. The Trust's primary objective is to successfully be the first in the world to reintroduce the white lion to the Greater Timbavati region. According to the conservation volunteering program, the trust operates within a contemporary conservation paradigm, "conservation through sustainable development, with particular emphasis on community participation, education and cultural upliftment" [8].

\subsection{The Tsau! White lion volunteer program}

The GWLPT's Tsau! White lion volunteer program will serve as the base for the research. Within this program volunteers may be involved in diverse activities to potentially satisfy their unfulfilled needs. "Candidates have a unique opportunity to gain hands-on experience whilst making a valuable contribution to the long-term conservation of the white lions"; and community participation is spread across different areas of engagement: a) education, b) cultural, by focusing on improving the circumstances for the local communities [8].

Since volunteer tourists select the respective volunteer program in which they wish to participate based on the hope of "aiding or alleviating" the circumstances within a selected environment (i.e. within the context of the Tsau! program), it can be said that individuals select this program due to their need to aid and alleviate the situation of the White Lions. The volunteer program therefore has a responsibility to compile a participant itinerary which can potentially satisfy the volunteer's need to aid and should offer need-fulfilling activities.

\subsection{Volunteer activities available at WLT}

Lion monitoring that offers volunteers the opportunity to engage in: lion-tracking, GIS mapping, recording of lion behaviour and veterinary care of lions;

Anti-Poaching activities include: fence maintenance, fence patrol with security team, dawn, dusk and midnight security patrols and anti-poaching techniques with Wild-Life Manager;

Administrative assistance: assistance with workshops and general office administration;

Habitat management includes: bush-thinning, erosion control and alien plant control;

Lion predation activities include: supplementary feeding, boma cleaning and game capture;

Scientific Research: predator and/or prey study and data capturing of research information; 
Cultural Participation as an additional activity includes: visit to Mafunyani village, skills transfer to local crafters and cooking traditional meals for a staff evening;

Community Development activities include: educational programmes (literacy and numeracy training), organic food-growth/gardening and eco-construction of infrastructure;

Natural Exploration includes: on-foot animal tracking and bird-viewing with Wildlife Manager;

Optional Expeditions are at the volunteer's own expense. Some of these activities are: game-drive in neighbouring reserves, on-foot wilderness walks and day-trips to Kruger National Park;

Unique team contribution activities depend on talent or profession, such as photography, writing skills that can make a unique contribution to the White Lion project or its associate projects.

"Students, who join our program, experience our project as a turning point in their lives, in terms of personal growth, understanding of their life's purpose, a deepening sense of value and values, spiritual growth, and a genuine commitment to making a difference" [8].

Certain respondents, according to Brown [4:488], have described feelings "...that they do well in life and wanted to give back." These individuals are more likely to participate in a "trip with a purpose" since it offers them the opportunity to help instead of travelling purely for self-enjoyment.

\section{Methodology}

\subsection{Sampling Design}

The target population for this study are: a) volunteers who are currently participating in the Tsau! White lion volunteer program (qualitative research); and b) volunteers who have in the past participated in this volunteer program (quantitative research). No particular demographic or sociographic population parameters exist within the units of analysis. The study includes all individuals as volunteers acquainted with the Tsau! volunteer program, regardless of age, gender or experience [11].

Non-probability sampling is used since no random selection from the volunteer population is done. The population of volunteers included in this study is a small sample; hence the entire population is included in the research.

\section{2 Sample Size}

Qualitative research was conducted on site in the Timbavati Private Game Reserve at the GWLPT conservatory. The volunteer program limits its number of participants at one time to eight volunteers. Two focus groups were conducted with all the volunteers on site participating in the program. The population size is therefore small (a limitation)) and the entire population of volunteers was researched. Trends, however, within this small sample size are probable since all the volunteers exhibit one common trait - they have all selected this particular volunteer program to participate in.

Quantitative research was conducted with past volunteers at the program via email correspondence. Using the GWLPT's database of previous volunteer participants, a questionnaire was emailed to all these respondents. The size of the Tsau! White lion volunteer program's database of 40 individuals was used therefore no population sample was identified. Limitations exist within the quantitative sample size since the sample size was also smaller than preferred.

\section{Data Collection}

The limited amount of available respondents for the quantitative research called for a mixed method approach. During the on-site visit to the Timbavati, qualitative research was conducted through two focus groups with eight volunteers per group. To obtain information in-depth analysis was done with the focus groups, observations recorded and communication documented [11]. [3] researched 
volunteer tourism and her data collection method consisted of "a qualitative focus group and semistructured in depth interviews..." [3].

Quantitative data collection was an e-mailed survey questionnaire to past volunteer respondents. As most participants are foreigners, geographically they could not be interviewed in person. Reasons for also using a quantitative approach were that: a) the study was explanatory and b) number of respondents was limited for data collection [11]. Quantitative data collection is advantageous as it translates findings into statistical data and allows comparisons between findings; its disadvantage is that it fails to capture in-depth or complex emotion.

The final data collection instruments for collecting the quantitative and qualitative data were refined until both the interview schedule (qualitative) and questionnaire (quantitative) matched the research objectives of the study. For both appropriate measurement scales were used, such as Likert scales for a particular question. The focus group discussion schedule contained the same questions as for the online quantitative survey.

\section{Findings}

Table 1. Summary of findings of the Two Focus Groups

\begin{tabular}{|c|c|c|c|}
\hline Questions & Group 1 & Group 2 & Consolidated findings \\
\hline 1. age and gender & \begin{tabular}{|l|}
$83 \%$ Female \\
$18-24$ years $\&$ \\
$35-44$ years \\
\end{tabular} & $\begin{array}{l}75 \% \text { Female } \\
18-24 \text { years }\end{array}$ & $\begin{array}{l}\text { All respondents were female, most } \\
\text { between } 18-24 \text {, with a small number } \\
\text { between } 35-44\end{array}$ \\
\hline $\begin{array}{l}\text { 2. what is the duration of } \\
\text { the program }\end{array}$ & $\begin{array}{l}2 \text { weeks }-4 \\
\text { months }\end{array}$ & 2-4 weeks & $\begin{array}{l}\text { Minimum duration was } 2 \text { weeks, max } \\
\text { was } 4 \text { months }\end{array}$ \\
\hline $\begin{array}{l}\text { 3. are you currently } \\
\text { employed? }\end{array}$ & Most not & none & $\begin{array}{l}\text { Majority of the volunteers were not } \\
\text { employed at the time }\end{array}$ \\
\hline $\begin{array}{l}\text { 4. reasons for participating } \\
\text { in the WLT program? }\end{array}$ & $\begin{array}{l}\text { Work by WLT } \\
\text { fascinating; was } \\
\text { the "only place } \\
\text { that felt right" }\end{array}$ & $\begin{array}{l}\text { Love animals, esp } \\
\text { lions; an uncommon } \\
\text { experience, meet } \\
\text { different people/ } \\
\text { cultures. }\end{array}$ & $\begin{array}{l}\text { Found work done by WLT } \\
\text { exceptional; loved animals and lions; } \\
\text { keen to meet different cultural groups } \\
\text { of people }\end{array}$ \\
\hline $\begin{array}{l}\text { 5. what was your } \\
\text { motivation to attend the } \\
\text { program? }\end{array}$ & $\begin{array}{l}\text { To see and work } \\
\text { with the white } \\
\text { lions } \\
\end{array}$ & $\begin{array}{l}\text { Love for animals and } \\
\text { love for Africa }\end{array}$ & $\begin{array}{l}\text { Love for the white lions and wished } \\
\text { to work with them }\end{array}$ \\
\hline $\begin{array}{l}\text { 6. the meaning of the word } \\
\text { 'volunteer' }\end{array}$ & $\begin{array}{l}\text { 'to give back'; 'to } \\
\text { explore, exchange } \\
\text { knowledge and } \\
\text { experience }\end{array}$ & $\begin{array}{l}\text { 'to help'; be useful \& } \\
\text { give of your time'; } \\
\text { getting to know } \\
\text { people and seeing } \\
\text { other lifestyles }\end{array}$ & $\begin{array}{l}\text { To help, to give back, to give of your } \\
\text { time. To explore other lifestyles and } \\
\text { exchange knowledge }\end{array}$ \\
\hline $\begin{array}{l}\text { 7. external factors that } \\
\text { influenced your decision }\end{array}$ & $\begin{array}{l}\text { Social factor: } \\
\text { concerns about } \\
\text { well-being of } \\
\text { lions and all } \\
\text { animals }\end{array}$ & $\begin{array}{l}\text { Social: participate in } \\
\text { program and meet } \\
\text { people; Economic: } \\
\text { SA is an affordable } \\
\text { destination }\end{array}$ & $\begin{array}{l}\text { Social factors: well-being of lions; } \\
\text { meet people } \\
\text { Economic factors: SA an affordable } \\
\text { destination }\end{array}$ \\
\hline $\begin{array}{l}\text { 8. in which activities did } \\
\text { you participate? }\end{array}$ & $\begin{array}{l}\text { All, except anti- } \\
\text { poaching and } \\
\text { admin activities }\end{array}$ & $\begin{array}{l}\text { All, except, unique } \\
\text { team contribution } \\
\text { and admin assistance }\end{array}$ & $\begin{array}{l}\text { All activities, except admin activities } \\
\text { and less in anti-poaching and unique } \\
\text { team contribution }\end{array}$ \\
\hline
\end{tabular}

Qualitative data was analysed using content analysis and the quantitative date was analysed using Qualtrics, the results are incorporated into paragraph 7: Discussion of results.

Given the objectives identified at the outset the following correlations between the objectives and research findings were made:

- to determine what motivates individuals to participate in a selected volunteer program, i.e. The Tsau! White lion volunteer program. 
The identified factors of motivation for an individual to participate in a chosen volunteer program include a large variety. The majority of the respondents in both the qualitative and quantitative research identified a love for animals and a need to help as their primary (intrinsic) factor of motivation to participate in the volunteer program. The White Lions themselves also served as a motivating factor since volunteers want to see the white lions in their natural habitat.

Respondents were asked to state what the term 'volunteer' meant to them, and responded with statements of altruism. When taking into consideration Maslow's theory of Human Motivation, "...motivations derive from a real or perceived need and the majority of respondents made the following associations with volunteerism: to give back, to support and to positively impact. All of these factors, as identified by [12], attribute to a sense of altruism, which, according to both [7, 10] attribute to a sense of self-transcendence and self-actualisation intrinsically in individuals. Motivating factors that increase a volunteer's willingness and propensity to volunteer can therefore be attributed to an individual's pursuit of altruism. Motivating factors of the volunteers at the Tsau! White lion volunteer program can be summarised as: a love for animals, a need to help the white lions, to give back, to support and positively impact.

- to determine the external factors that influence volunteers in their choice of this selected program, i.e. The Tsau! White lion volunteer program.

This objective poses which external factors influence volunteers in their choice of a selected program. External factors of influence affecting individual's decision to participate includes time pressures from employment, financial barriers, mobility issues and lack of knowledge about volunteering opportunities [2].

Environmental factors had the greatest impact on volunteer's propensity as to whether or not to volunteer in the program. The recurring theme is the concern for the well-being of the lions. The macro factors with the least amount of applicability are technological, legal and political factors. External influences are also significantly impacted by their external sources of information about the particular program. Majority of the volunteers (in both qualitative and quantitative) responded that the internet was their primary source of information. Other channels of communication included: educational institutions, Linda Tucker's [13] book, an agency, a documentary and through friends and relatives, to name a few.

The perceived benefits derived from participating in a volunteer program can increase or decrease an individual's propensity as to whether or not to participate in the identified program. A recurring theme of the perceived benefits being the strong references to the white lions themselves. The most identified benefit from participating in the volunteer program is to experience a unique trip and to participate in meaningful volunteer work. Respondents also indicated an interest in better understanding the management of these lions, as well as the benefit of giving back to the world.

With regard to defining volunteer tourists - respondents wished to participate to "aid or alleviate". An individual's need for self-actualisation and self-transcendence motivates them intrinsically to participate in volunteer programs to assist in fulfilling a need for altruism that leads to the assumption that no matter how intrinsically motivated an individual is to participate in volunteer programs, external factors (e.g. time, money) are still main determinants of participating.

The available external channels of information about the program are also important and relevant since these channels (for example via the internet - the Tsau! White Lion Protection Trust's website), are the first interaction the volunteer has with the program itself.

\section{Discussion of Results}

Internal and external factors influence an individual's motivation to participate in volunteer programs. These programs include the GWLPT that offers individuals the opportunity to participate in a wildlife volunteer program. This is an example of 'supply meeting demand' since international volunteer programs are growing and developing. Both [7, 10] identified motivational and need theories which validate the purpose an individual finds within volunteerism. The research indicates a correlation between these theories and the motivations of volunteers in fulfilling a need for self-actualisation or 
self-transcendence. This volunteer program, by offering the mentioned activities assists participating volunteers in fulfilling these needs.

Internal factors of motivation are also associated with factors such as age and gender and in both the quantitative and qualitative research, the greater percentages of volunteers are female.

Most volunteers participate in the volunteer program for only two or four weeks, with few engaging for longer. The average cost incurred was in the region of $02000-\square 2500$. Most of the respondents indicated that they are not employed possibly indicating a 'gap' year.

Volunteers' nationalities varied with the majority being foreigners including: American, Australian, Belgian, Brazilian, British, German, Hungarian, Italian, South African and Swiss, with the majority of the volunteers either from the UK or USA.

The reasons why volunteers participated in the Tsau! White lion volunteer program and the motivation behind participating can be summarised as: a love for animals, a need to help, the white lions, to give back, to support, positively impact, to explore, to help and to improve a situation. External factors influencing decisions whether or not to participate in the program included: environmental, social and economic factors.

Benefits derived from participating in the volunteer program's activities included: experiencing a unique trip, participating in meaningful volunteer work and engaging with the lions themselves. This suggests that volunteers are intrinsically (emotionally) influenced or driven when deciding on participation. Most indicated that they would recommend the program to other individuals.

The limitations of this research can be attributed to volunteer tourism being a niche market with limited numbers of volunteers that participate in such programs. The size of the sample population was therefore a limitation since the sample, for both qualitative and quantitative, was small.

Future research could include studying what volunteers want from a particular volunteer program that could better inform volunteer programs on what to offer volunteers. Other studies could include studying the psychological characteristics and what causes certain individuals to have a higher propensity towards volunteering in similar projects than other individuals.

\section{Conclusion}

There is a market demand for volunteer programs irrespective of why individuals choose to participate in them. The GWLPT serves as the basis for research as to whether individual's needs are being met once they have chosen and participated in the program. Volunteerism stimulates tourism and to develop a volunteering culture within a country, either formal or informal, is a remarkable feat since the essence of volunteerism in practise is an honourable occurrence. South Africa has a vast variety of wildlife potential and to use volunteering programs to further the conservation and development thereof is a worthwhile application thereof.

The GWLPT strives to fulfil the needs of volunteers, especially intrinsic needs associated with self-actualisation and self-transcendence. With on-going positive experiences by volunteers who are engaging in these programs, as well as positive word-of-mouth, the continued growth and livelihood of these programs can be ensured since they not only benefit the cause they are assisting with, but the individuals who volunteer in the programs also benefit personally.

\section{References}

1. Envision. Maslow's theory of motivation - hierarchy of needs. [Online] Available from: www.envisionsoftware.com/articles/Maslows_Needs_Hierarchy.html [Accessed: 12 April 2012] (2012)

2. K. Holmes, K. Smith, Managing volunteers in tourism. Oxford: Elsevier Ltd (2009)

3. S. Brown, Travelling with a Purpose: Understanding the Motives and Benefits of Volunteer Vacationers. Current Issues in Tourism, 8,6, 479-496 (2005) 
4. M.A. Benson, Volunteer tourism - Structuring the research agenda. In: Benson, A.M. (ed.) Volunteer tourism - theory framework to practical applications. New York \& Oxon: Routledge. (2011)

5. A. Coghlan, Exploring the role of expedition staff in volunteer tourism, International Journal of Tourism Research, 10, 183-191 (2008)

6. J.L. Lipp, Informal Volunteer Recognition - Creating a Culture of Appreciation [Online]. Available from: www.energizeinc.com/ener/documents/ER_SIGuide_SAMPLE.pdf [Downloaded: 5 April 2012] (2011)

7. A. H. Maslow, Motivation and Personality. New York: Harper \& Row Publishers.

8. The Global White Lion Protection Trust. About us. [Online] Available from: http://www.whitelions.org/index.php?option=com_content\&view=article\&id=40\&Itemid=28 [Accessed: 28 March 2012]. (2011)

9. P.J. Du Plessis, G.G. Rousseau, C. Boshoff, L. Ehlers, M. Engelbrecht, R. Joubert, and S. Sanders, S. Buyer behaviour - Understanding consumer psychology and marketing. Cape Town: Oxford University Press Southern Africa (2007)

10. V. E. Frankl, Man's search for meaning. New York: Washington Square Press.

11. G.M. Du Plooy, Communication Research: techniques, methods and applications. Lansdowne: Juta. (2009)

12. Z. Alexander, A. Bakir, A. Understanding voluntourism - A Glaserian grounded theory study. In: Benson, A.M. (ed.) Volunteer tourism - theory framework to practical applications. New York \& Oxon: Routledge (2011)

13. L. Tucker, Saving the White Lions: One woman's battle for Africa's most sacred animal. Berkley (CA): North Atlantic Books (2013) 